\title{
Spinal Subdural Haematoma in A Patient After Dobutamine Stress Test: An Unusual Occurrence
}

\author{
Imranullah Hashmi ${ }^{\mathrm{a}, \mathrm{d}}$, Sreedhar Kolli ${ }^{\mathrm{b}}$, Ravindra Nannapaneni ${ }^{\mathrm{c}}$
}

\begin{abstract}
Spinal subdural haematoma is a rare entity and commonly due to spinal pathology. Its occurrence in patients with impaired coagulation has been reported. We report a case of spinal haematoma occurring after dobutamine stress test. Prompt diagnosis of such cases is required which can be done with MRI spine. Early intervention with surgery and removal of clot causing compression can prevent permanent disability. Our patient developed excruciating back pain and paraplegia after dobutamine stress test. Initially treated with antibiotics and fluids for suspected urinary tract infection, neuroimaging later revealed spinal haematoma. Though surgical evacuation resulted in some improvement in neurology, she was left with a significant disability. It can be concluded that spinal haematoma should be suspected in any patient who complains of severe back pain with neurological symptoms. It needs prompt diagnosis and treatment to prevent disability.
\end{abstract}

Keywords: Spinal subdural haematoma; Dobutamine stress test

\section{Introduction}

Dobutamine stress test is commonly used in the assessment

Manuscript accepted for publication October 5, 2011

${ }^{a}$ Specialty Registrar, Neurological Rehabilitation unit, Moseley Hall Hospital, Birmingham, United Kingdom

${ }^{\mathrm{b}}$ Consultant Spinal Rehabilitation Unit, Rookwood Hospital, Cardiff, United Kingdom

${ }^{\mathrm{c} C}$ Consultant Neuro-surgery, University Hospital Wales, Cardiff, United Kingdom

${ }^{\mathrm{d}}$ Corresponding author: Imranullah Hashmi, Flat 1, 113 Sandford Road, Birmingham, United Kingdom. B13 9BU.

Email: hashminet@yahoo.com of patients with ischemic heart disease. Adverse effects are reported to occur in up to $75 \%$ of cases which include ST segment changes on ECG (in up to $50 \%$ cases), chest pain, palpitations and significant supraventricular and ventricular arrhythmias. Various case reports published in literature show occurrence of broken heart syndrome (Takotsubo syndrome) [1-3] prolonged left ventricular dysfunction [4], transient global amnesia [5], cardiac rupture [6] and papillary muscle rupture [7]. We describe a case of spinal subdural haematoma occurring as adverse effects of dobutamine stress test, which to our knowledge, has not been reported in the literature so far. This case also highlights the importance of early recognition and treatment of a similar situation.

\section{Case Report}

A 76 years old independent lady underwent the dobutamine stress test for assessment of ischemic heart disease. The test did not reveal myocardial ischemia. During the test she experienced symptoms of headache and dry mouth which improved after retiring to bed early in the evening. On waking the next morning, she experienced severe, sharp pain in her lumbar spine area more so on left side, radiating downwards. The pain worsened with movements and was associated with a dry mouth. There was no history of fall or trauma to the back. She was seen by the family physician and was thought to be dehydrated secondary to a urinary tract infection and was started on treatment. Despite treatment for 3 days her pain was progressively worsening, therefore she was admitted to the hospital. Her past medical history included hypertension, ischemic heart disease, one episode of transient ischemic attack 10 years previously, and atrial fibrillation for which she was on Warfarin treatment with good INR control. Other medication included Carvedilol, Simvastatin, Digoxin, Furosemide and Valsartan.

At the time of admission to hospital, neurological examination revealed a normal gait, power of $5 / 5$ in all limbs, normal reflexes and intact sensation. Blood results showed a raised white cell count of 12.5, ESR of 37, creatinine of 109 and INR of 2.5. She was diagnosed to have pyelonephritis and was started on antibiotics.

doi: $10.4021 / \mathrm{jmc} 381 \mathrm{w}$ 
She developed urinary retention the day after admission and was catheterised. She also complained of weakness of her left leg, examination of which revealed a reduced power of $3 / 5$ in proximal muscle groups and $2 / 5$ in distal muscle groups of the left leg. Power in the right leg was normal. Sensory examination was normal. Anal tone and perianal sensation was normal. On the next day, she was reviewed by the neurosurgical team and an urgent MRI scan of spine was requested. Neurological examination now showed deterioration with a power of $0 / 5$ in the left leg, and $2 / 5$ in the right leg proximally and $0 / 5$ distally. The scan showed a spinal subdural haematoma at level of T9/T10 displacing the cord to the right side. She was commenced on treatment for reversal of coagulation and prepared for surgery. She underwent dorsal spinal laminectomy at level of T7-T11 and evacuation of haematoma. Postoperatively, some neurological improvement was noted.

Later, she was transferred to the spinal rehabilitation unit where she underwent rehabilitative treatment for 8 months and was discharged home. At the time of discharge she was left with a power of 3/5 in right leg and 2/5 in left leg. Her bladder was managed with a suprapubic catheter due to loss of bladder function her bowels were managed with suppositories and manual evacuation. Due to her disabilities, she needed care assistance at home for washing and dressing, adaptations at home and a powered wheelchair for mobilisation.

\section{Discussion}

Spinal cord haematoma is a rare entity and commonly due to a spinal pathology like vascular malformations, trauma, spinal surgery, tumour, abscess or inflammatory myelitis. Intrinsic [8,9] and acquired [10-13] coagulation abnormalities are attributed as cause in cases where they are present in absence of primary cord pathology. Deger SM et al [14] described a case of spontaneous spinal haematoma in a patient on haemodialysis. Lumbar and C1-C2 spinal puncture is also reported as a cause $[15,16]$. This case report describes development of spinal subdural haematoma after a dobutamine stress test.

Dobutamine is a synthetic catecholamine which directly stimulates beta 1 and beta 2 receptors. There is dose related increase in heart rate, myocardial contractility and blood pressure. Dobutamine stress test is used to look for any myocardial ischemia under stress in patients in which routine exercise testing is contraindicated due to chronic debilitation, decreased functional capacity due to old age or physical problems like injury, arthritis etc. Other candidates for this test include patients on negative chronotropic agents like beta blockers that would inhibit the ability to achieve adequate heart response. In this lady dobutamine stress test was requested as she had $80 \%$ mid left anterior descending coro- nary artery stenosis on angiography and hypokinesia of left ventricular wall on echocardiography suggesting ischemia of myocardium. Her INR control was good during the time of test, and she developed symptoms after the test. Therefore it is the most possible cause for development of spinal cord haematoma.

Regardless of aetiology, the principal initial symptom of spinal cord haematoma is excruciating back pain in the region of the haematoma and the underlying pathology. Neurological deficit also relates to the site of haematoma and may include variable degrees of motor, sensory and autonomic disturbances. It may occur acutely along with pain or may present after 2-24 hours or maybe even days. Spinal haematoma requires prompt diagnosis and MRI spine is the investigation of choice. It demonstrates both the haematoma and the underlying pathology. It would also demonstrate other underlying pathologies in the absence of a spinal haematoma [17]. Management of such cases includes an urgent reversal of any intrinsic or acquired coagulopathy and surgery to prevent neurological damage. Lawton et al [18] reported better neurological outcomes in patients who underwent surgery within 12 hours of onset of symptoms and fair to good motor function below injury level (Frankle Grade D). McQuarrie et al [19] showed that a delay of more than 6 hours prior to surgery reduces probability of recovery. Foo and Rossier [20] concluded that recovery depends on the preoperative neurological condition of patient.

\section{Conclusion}

This case illustrates development of spinal subdural haematoma in a patient after dobutamine stress test. Aside from above mentioned adverse effects, no literature indicates occurance of such complication. Though our patient was on warfarin treatment, but good INR control around the time and occurrence of symptoms right after the test indicate it to be the most likely cause.

Furthermore, the diagnosis of spinal subdural haematoma is often delayed despite availability of the modern imaging techniques. Prompt treatment with surgery can prevent damage to the cord and permanent disability.

\section{References}

1. Vasconcelos Filho FJ, Gomes CA, Queiroz OA, Barreto JE. Dobutamine stress echocardiography-induced broken heart syndrome (Takotsubo Syndrome). Arq Bras Cardiol. 2009;93(1):e5-7.

2. Margey R, Diamond P, McCann H, Sugrue D. Dobutamine stress echo-induced apical ballooning (Takotsubo) syndrome. Eur J Echocardiogr. 2009;10(3):395-399.

3. Sonmez O, Duman C, Duzenli MA, Tokac M. Special attention for elderly women: atypical left ventricular api- 
cal ballooning syndrome induced by dobutamine stress test: a case report. J Am Geriatr Soc. 2009;57(9):17351736.

4. Muller H. Dobutamine stress induced severe prolonged left ventricular dysfunction. Arch Cardiovasc Dis. 2008;101(6):429-430.

5. Saura D, Penafiel P, Morales A, Albert L, Martinez F, de la Morena G, Valdes-Chavarri M. Transient global amnesia after dobutamine--atropine stress echocardiography. Eur J Echocardiogr. 2008;9(4):567-568.

6. Kemdem A, Briki R, Lemaitre F, Jahjah L, Guimfacq V, Sakabenis D, Matouk M, et al. Rupture of papillary muscle during dobutamine stress echocardiography. Ann Cardiol Angeiol (Paris). 2010;59(2):100-102.

7. Nadeem SN, Hassan K, Kazmi KA, Sharif HM, O’Neill B. Cardiac rupture during stress echocardiography. Can J Cardiol. 2005;21(13):1217-1219.

8. Schenk VW. Haemorrhages in Spinal Cord with Syringomyelia in a Patient with Haemophilia. Acta Neuropathol. 1963;3:306-308.

9. Wisoff JH, Rovit RL, Ho V, Leventhal H. Spontaneous hematomyelia secondary to factor XI deficiency. Case report. J Neurosurg. 1985;63(2):293-295.

10. Heppner PA, Monteith SJ, Law AJ. Spontaneous spinal hematomas and low-molecular-weight heparin. Report of four cases and review of the literature. J Neurosurg Spine. 2004;1(2):232-236.

11. Cha YH, Chi JH, Barbaro NM. Spontaneous spinal subdural hematoma associated with low-molecular-weight heparin. Case report. J Neurosurg Spine. 2005;2(5):612613.

12. Dampeer RA. Spontaneous spinal subdural hematoma:
Case study. Am J Crit Care. 2010;19(2):191-193.

13. Kyriakides AE, Lalam RK, El Masry WS. Acute spontaneous spinal subdural hematoma presenting as paraplegia: a rare case. Spine (Phila Pa 1976). 2007;32(21):E619-622.

14. Deger SM, Emmez H, Bahadirli K, Kale A, Ebinc FA, Turkoglu M, Arinsoy T, et al. A spontaneous spinal epidural hematoma in a hemodialysis patient: a rare entity. Intern Med. 2009;48(24):2115-2118.

15. Pobiel RS, Schellhas KP, Eklund JA, Golden MJ, Johnson BA, Chopra S, Broadbent P, et al. Selective cervical nerve root blockade: prospective study of immediate and longer term complications. AJNR Am J Neuroradiol. 2009;30(3):507-511.

16. Miyakoshi N, Hongo M, Kasukawa Y, Ando S, Shimada Y. Thoracic disk herniation with hematoma--case report. Neurol Med Chir (Tokyo). 2008;48(9):414-417.

17. Trautner S, Pedersen H, Bendtson I. Neuromyelitis optica with atypical cerebral lesions demonstrated by magnetic resonance imaging in a 9-year old girl. Ugeskr Laeger. 2009;171(5):334-336.

18. Lawton MT, Porter RW, Heiserman JE, Jacobowitz R, Sonntag VK, Dickman CA. Surgical management of spinal epidural hematoma: relationship between surgical timing and neurological outcome. J Neurosurg. 1995;83(1):1-7.

19. McQuarrie IG. Recovery from paraplegia caused by spontaneous spinal epidural hematoma. Neurology. 1978;28(3):224-228.

20. Foo D, Rossier AB. Preoperative neurological status in predicting surgical outcome of spinal epidural hematomas. Surg Neurol. 1981;15(5):389-401. 